\title{
BEST PRACTICE STRATEGI LAYANAN BIMBINGAN DAN KONSELING SELAMA SCHOOL FROM HOME PADA SISWA MELALUI MEDIA WHATSAPP INTERAKTIF
}

\author{
SUPRAPTINI \\ SMAN 1 Tanjungsari \\ E- mail: supraptini445@gmail.com
}

\begin{abstract}
ABSTRAK
Penulisan Best Practice ini bertujuan untuk: (1) Mengakomodir layanan bimbingan konseling yang dibutuhkan siswa selama school from home, sehingga dapat meminimalis dari setiap permasalahan yang dihadapi. (2) Membantu individu agar dapat mencapai kehidupan dengan kualitas pribadi yang memahami realitas, dalam pemenuhan kebutuhannya dengan kerangka kerja yang telah ditentukan dan (3) Melatih siswa tentang apa yang seharusnya dilakukan dalam hidupnya, dengan mempergunakan norma yang berlaku, bertingkah laku secara tanggung jawab, serta memahami dan mampu menghadapi kenyataan. Teknik yang digunakan dalam layanan kegiatan adalah secara daring dengan melalui media WhatsApp interaktif. Pelayanan Bimbingan dan Konseling bersifat For All, Agar tetap bisa memberikan layanan dalam situasi yang tidak memungkinkan bisa bertemu secara langsung/tatap muka, maka WhatsApp Interaktif ditetapkan sebagai media yang familier, terjangkau, dan bisa diakses oleh sebagian besar siswa. Keberhasilan yang diperoleh dalam pelaksanaan pembimbingan mencapai $80 \%$ siswa mengikuti kegiatan dari jumlah peserta yang ada.
\end{abstract}

Kata Kunci: Layanan Bimbingan dan Konseling, School From Home, WhatsApp Interaktif

\section{PENDAHULUAN}

Bimbingan dan Konseling sebagai bagian integral yang tak terpisahkan dari sistem pendidikan memiliki peran penting dan strategis dalam mendukung pencapaian tujuan pendidikan secara komprehensif. Menurut Setiyanie (2020), Guru Bimbingan dan Konseling bertugas untuk membantu pencapaian tujuan pendidikan nasional, peserta didik atau konseli untuk memaksimalkan perkembangannya secara optimal, sukses, mandiri, sejahtera, dan bahagia dalam kehidupannya. Lalu bagaimana peranan Guru Bimbigan dan Konseling dalam pembelajaran daring. Berbeda dengan peranan guru mata pelajaran, layanan Bimbingan dan Konseling tidak memberikan materi-materi ataupun tugas-tugas yang malah memberatkan siswa. Guru Bimbingan dan Konseling memberikan layanan yang mengakomodir dalam pencapaian tugas perkembangan peserta didik, sehingga siswa memiliki kecakapan hidup dan menjadi pribadi yang mandiri. Hal ini tidak luput dengan peran guru Bimbingan dan Konseling dalam menjalin komunikasi yang baik dengan orang tua peserta didik (Darwanto,2020)

Berdasarkan uraian di atas, penulis mencoba untuk mengulas tentang strategi layanan Bimbingan dan Konseling pada siswa selama school from home melalui media WhatsApp interaktif. Hal ini sejalan dengan pendapat Zhang Dkk. (2004), bahwa penggunaan internet dan teknologi multimedia mampu merombak cara penyampaian pengetahuan dan dapat menjadi alternatif pembelajaran yang dilaksanakan dalam kelas tradisional. (Zhang Dkk., 2004)

Mengingat bahwa pekerjaan Bimbingan dan Konseling itu tidak hanya melayani siswa yang datang ke ruang Bimbingan untuk konsultasi atau pun memanggil siswa bermasalah untuk di konseling, melainkan dalam layanan pengembangan siswa itu diharapkan guru Bimbingan dan Konseling lebih banyak melaksanakan kegiatan layanan yang bersifat pencegahan dan ini lebih banyak dilakukan di layanan dasar. E-learning mencakup empat elemen fitur: 1) konten yang relevan dengan tujuan pembelajaran, 2) menggunakan metode pembelajaran, 3) menggunakan elemen media, dan 4) membangun pengetahuan dan keterampilan baru. (Punaji Setyosari, 2007)

Tujuan artikel ini adalah : (1) Mengakomodir layanan bimbingan konseling yang dibutuhkan siswa selama school from home, sehingga dapat meminimalis dari setiap 
permasalahan yang dihadapi. (2) Membantu individu agar dapat mencapai kehidupan dengan kualitas pribadi yang memahami realitas, dalam pemenuhan kebutuhannya dengan kerangka kerja yang telah ditentukan. (3) Melatih siswa tentang apa yang seharusnya dilakukan dalam hidupnya, dengan mempergunakan norma yang berlaku, bertingkah laku secara tanggung jawab, serta memahami dan mampu menghadapi kenyataan. Untuk itu strategi layanan Bimbingan dan Konseling dengan media WhatsApp interaktif perlu untuk dilakukan, agar dalam situasi school from home, siswa tetap mendapatkan pelayanan dasar.

\section{METODE PELAKSANAAN KEGIATAN}

Kegiatan Layanan Bimbingan Konseling yang dilakukan adalah secara daring dan menggunakan media WhatsApp interaktif, yang sering disebut sebagai kulwap/kuliah via whatsApp. Prinsip kulwap adalah adanya kerelaan dari kedua belah pihak, baik dari peserta maupun pemateri. Penggunaan Kulwap disesuaikan dengan kontek kebutuhan siswa artinya, antara kegiatan layanan yang dilakukan sesuai dengan situasi dan kondisi yang yang terjadi. Misalnya, jika layanan kelompok, maka Kulwap dibentuk dengan group whatsapp, dan jika konseling individu, maka Kulwap dilakukan dengan melalui Wapri/Japri.

Ada beberapa hal yang dilakukan dalam penggunaan media Kulwap Interaktif, yaitu sebagai berikut : (1) Sebelum kegiatan terlebih dulu dilakukan kesepakatan antara siswa dan guru untuk kesamaan pemahaman, (2) Adanya kerelaan antara siswa dan guru, jadi tidak adanya paksaan diantara kedua pihak, (3) Siswa mempunyai peluang untuk mengajukan pertanyaan, atau tanggapan mengenai segala yang sesuai dengan kontek yang dihadapi, (4) Tata cara Kulwap sangat tergantung kebijakan penyelenggara kulwap, klasikal, kelompok atau individu, dan (5) Karena Kulwap itu meninggalkan hasil chat, keikutsertaan dan keaktifan siswa bisa dilihat melalui info group.

\section{HASIL DAN PEMBAHASAN}

\section{Hasil}

Keaktifan siswa mengikuti kegiatan dapat dilihat melalui info group, dengan hasil chat yang ditingglkan, contohnya seperti pada $\mathrm{Gb}$. berikut. :
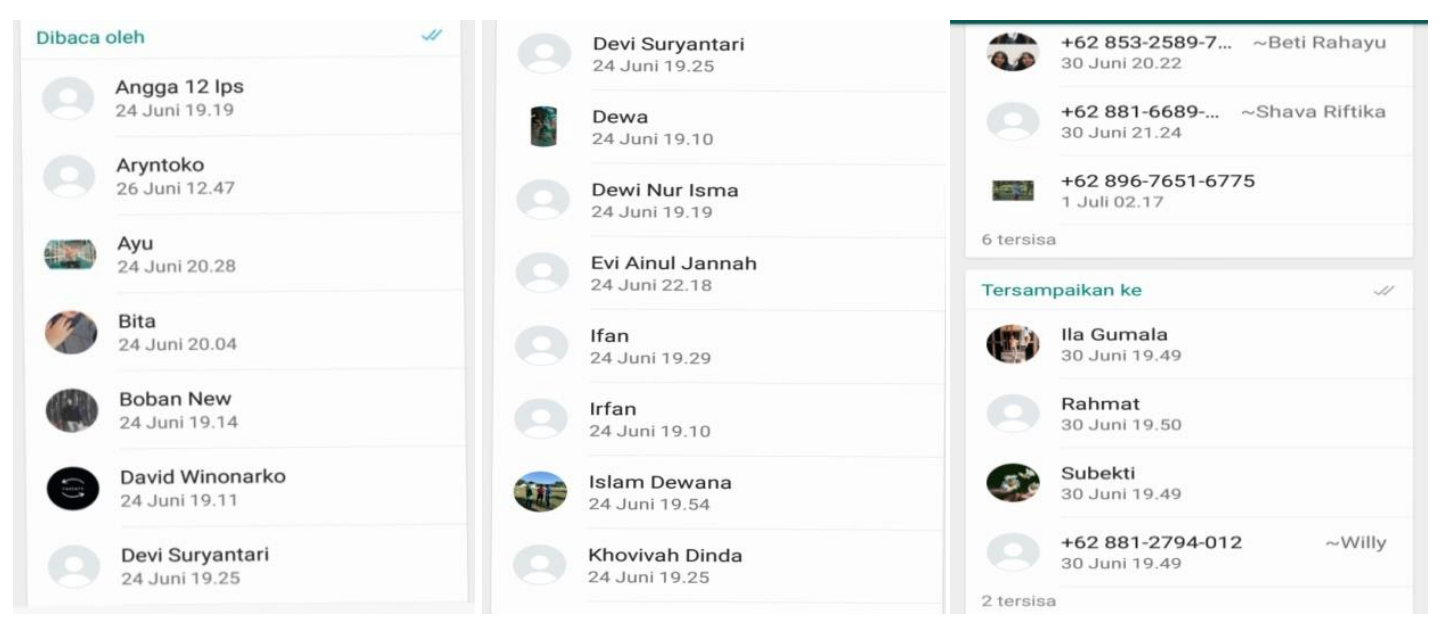

\section{Gambar 1. Screenshot WhatsApp}

Berdasarkan pemantauan, keikutsertaan siswa dalam kegiatan melalui media WhatsApp (Kulwap), dari 25 peserta rata-rata mencapai $80 \%$ siswa aktif mengikuti dan $20 \%$ yang lain belum mengikuti secara aktif. Dengan demikian layanan Bimbingan dan Konseling melalui WhatsApp interaktif dengan $80 \%$ menyumbang keberhasilan pelaksanaannya. Prosentase keberhasilan dapat diliaht melalui gambar sbb : 


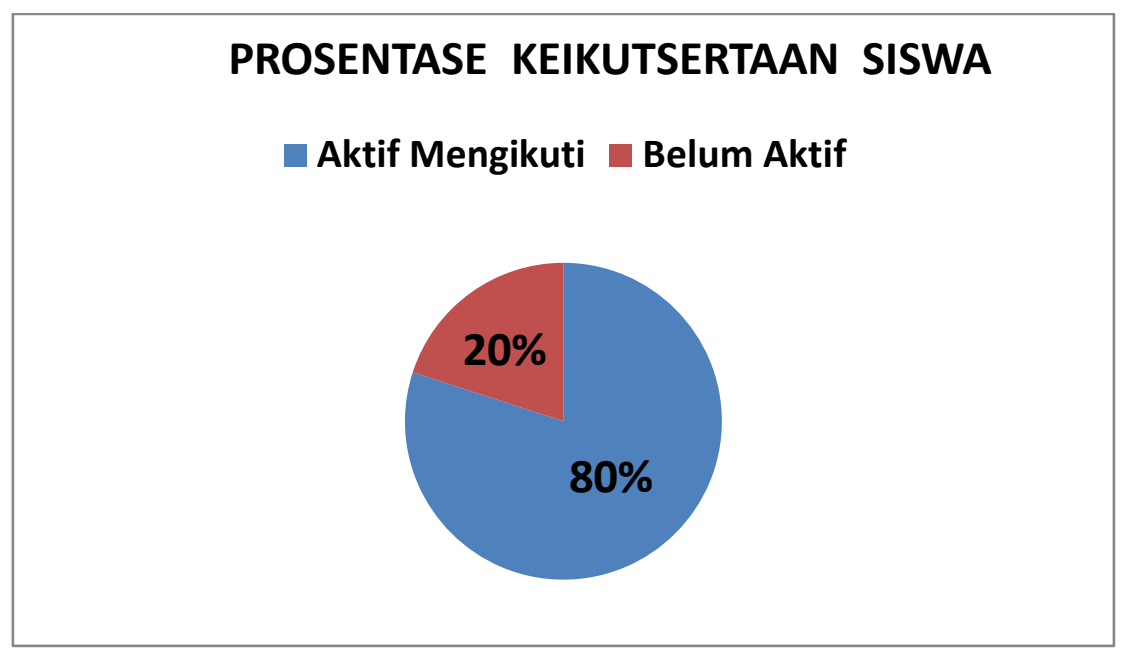

Gambar 2. Prosentase Keikutsertaan Siswa

Untuk ketercapaian dari target yang diprogramkan tentu saja tidak akan tercapai $100 \%$, akan tetapi dalam situasi yang tidak memungkinkan guru Bimbingan dan Konseling mengadakan pertemuan secara tatap muka, siswa sudah merasa adanya kehadiran guru Bimbingan dan Konseling dalam menemani, mendampingi mereka saat siswa menemui permasalahan ataupun kendala lain yang membutuhkan pemberian solusi. Kulwap atau kuliah via whatsApp merupakan media yang semua siswa menggunakan dan bisa mengaksesnya. Kulwap tidak sama dengan metode broadcast message, karena dalam kulwap ada kerelaan dari kedua belah pihak, yaitu peserta dan pemberi materinya. Langkah awal yang dilakukan dalam menggunakan proses pembelajaran menggunakan daring kombinasi whatsApp grup adalah membuat grup kelas di whatsapp dan mengundang semua anggota kelas tersebut. (Latjuba Sofyana \& Abdul Rozaq : 2019). Kunci keberhasilan kulwap ini adalah kerelaan kedua belah pihak, maka kita undang peserta untuk masuk ke dalam group khusus. tentunya, hanya mereka yang rela meluangkan waktu, dan rela membaca chat. Kulwap, aplikasi WA nya bisa disetting oleh admin dimana hanya admin yang bisa mengirim pesan. Baru setelah dirasa perlunya untuk memberi peluang pada peserta, maka adanya pertanyaan dan tanggapan, Admin kemudian membuka kunci settingnya, dan berlanjut terus sampai selesainya kesepakatan waktu yang ditentukan.

Idealnya, dalam satu kali kulwap, itu selain peserta dan pemateri, ada moderator yang memandu jalannya kulwap. Berhubung kulwap ini kita pake sebagai metode dalam layanan bimbingan klasikal secara daring, maka semua pekerjaan moderator sekaligus pemateri diambil oleh guru Bimbingan dan Konseling. Kegiatan dengan media Kulwap, tahapan-tahapannya bisa di ATM (Amati, Tiru dan Modifikasi) oleh siswa.

Menurut Moore, Dickson-Deane, \& Galyen dalam Ali Sadikin.Dkk (2020) Pembelajaran daring merupakan pembelajaran yang menggunakan jaringan internet dengan aksesibilitas, konektivitas, fleksibilitas, dan kemampuan untuk memunculkan berbagai jenis interaksi pembelajaran. Perkembangan e-learning terus berkembang mengikuti perkembangan teknologi, yang akan menjadi sistem pembelajaran di masa depan. Efektifitas dan fleksibilitas akan menjadi alasan utama. (Tiyas, 2014 dalam Nurhayati, 2020).

\section{Pembahasan}

Berbicara tentang layanan Bimbingan dan Konseling, dalam POP BK disebutkan bahwa layanan Bimbingan dan Konseling dapat diselenggarakan secara langsung dan melalui media. Secara ringkas, saya merangkumnya dalam sebuah tabel berikut : 
Tabel 1. Media Layanan Bimbingan dan Konseling

\begin{tabular}{|c|l|c|l|}
\hline \multicolumn{3}{|c|}{ METODE/CARA LAYANAN BIMBINGAN DAN KONSELING } \\
\hline \multicolumn{3}{|c|}{ LAYANAN LANGSUNG } & \multicolumn{2}{c|}{ LAYANAN MELALUI MEDIA } \\
\hline 1 & Konseling Individu & 1 & Melalui papan bimbingan \\
\hline 2 & Konseling Kelompok & 2 & Kotak masalah \\
\hline 3 & Bimbingan Kelompok & 3 & Pengembangan media, seperti: \\
\hline 4 & Bimbingan Klasikal & (inovatif) seperti : Leaflet, \\
\hline 5 & Bimbingan Kelas besar/ Lintas kelas & & Poster, booklet, banner, web \\
\hline 6 & Konsultasi & Blog, video interaktif, photo \\
\hline 7 & Kolaborasi & Voice,dll dengan memperhatikan \\
\hline 8 & Alih tangan kasus & Dukungan fasilitas/sarana,setting \\
\hline 9 & Kunjungan rumah & & Lay out, daya tarik, konten media, \\
\hline 10 & Advokasi & & penempatan, keterbacaan, komposisi, \\
\hline 11 & Konfrensi kasus & Dan daya tarik. \\
\hline
\end{tabular}

Karena tema kulwap kali ini tentang media layanan Bimbingan dan Konseling, maka sesuai dengan yang tertulis di POP, tujuannya adalah agar Guru bimbingan dan konseling atau konselor dapat membuat media secara kreatif dan inovatif serta memanfaatkan media sebagai upaya memaksimalkan layanan bimbingan dan konseling kepada peserta didik/konseli dengan Langkah-langkah seperti yang dijelaskan di POP.

Pengertian Kulwap yaitu melaksanakan layanan Bimbingan dan Konseling melalui media whatsApp, yang secara singkat disebut sebagai kulwap/kuliah via whatsApp. Prinsip kulwap adalah adanya kerelaan dari kedua belah pihak. baik dari peserta maupun pemateri. seperti kulwap kita sekarang. jika saya hanya share materi saja, itu disebut broadcast message, sangat sedikit peluang utk berinteraksi antara peserta maupun pemateri.

Konsultasi via WA (japri) ini bisa kita lakukan dan dokumentasikan untuk kita masukan ke dalam jurnal harian Bimbingan dan Konseling. Tanggal merekap sesuai format jurnal ataupun format laporan konsultasi (bisa mencontoh di lampiran POP BK). enaknya konsul via WA, kita bisa mudah merekap karena ada jejak chat. kelemahannya, kita tidak bisa melihat ekspresi mereka yang konsultasi. Obrolan di WA bisa berubah menjadi layanan konseling individu jika langkah-langkahnya disesuaikan dengan langkah-langkah pelaksanaan konseling individu. pun demikian dengan obrolan di group WA. seperti kulwap ini, jika dijadikan metode dalam layanan klasikal, maka tahapannya harus disesuaikan dengan RPL yang kita buat untuk layanan bimbingan klasikal

Kulwap ini memerlukan persiapan,. biasanya bisa berupa pengumuman dulu beberapa hari menjelang kulwap. Harapannya, bisa menemukan waktu yang tepat dan siswa-siswa pun bisa mempersiapkan diri (termasuk mencari tempat yang bisa akses jaringan dan android untuk ikut kulwap). Melalui cara ini bisa lebih efektif (80\% siswa aktif) dibanding kita sekedar ngobrol di group WhattApp siswa yang sudah ada.

Dalam konsep Bimbingan dan Konseling perkembangan, bimbingan klasikal merupakan salah satu kegiatan yang dapat dilakukan oleh guru Bimbingan dan Konseling dalam komponen layanan dasar. Hal ini tertuang dalam Permendikbud nomor 111 tahun 2014 tentang Bimbingan dan Konseling pada Pendidikan Dasar dan Menengah. Layanan dasar dapat dikatakan sebagai bentuk penegasan paradigma baru pelayanan bimbingan dan konseling di sekolah yang berorientasi pada perkembangan (Developmental Guidance and Counseling) dan model bimbingan dan konseling komprehensif (Comprehensice Guidance and Counseling) dimana upaya bimbingan dan konseling lebih mengedepankan pelayanan yang bersifat preventif dan pengembangan, menggantikan paradigma lama yang lebih berorientasi pada pendekatan kuratif-klinis. 
Untuk mengetahui tentang porsi Bimbingan dan Koseling dalam pendidikan, maka bisa dilihat melalui gambar wilayah pelayanannya dalam jalur pendidikan sebagai berikut :

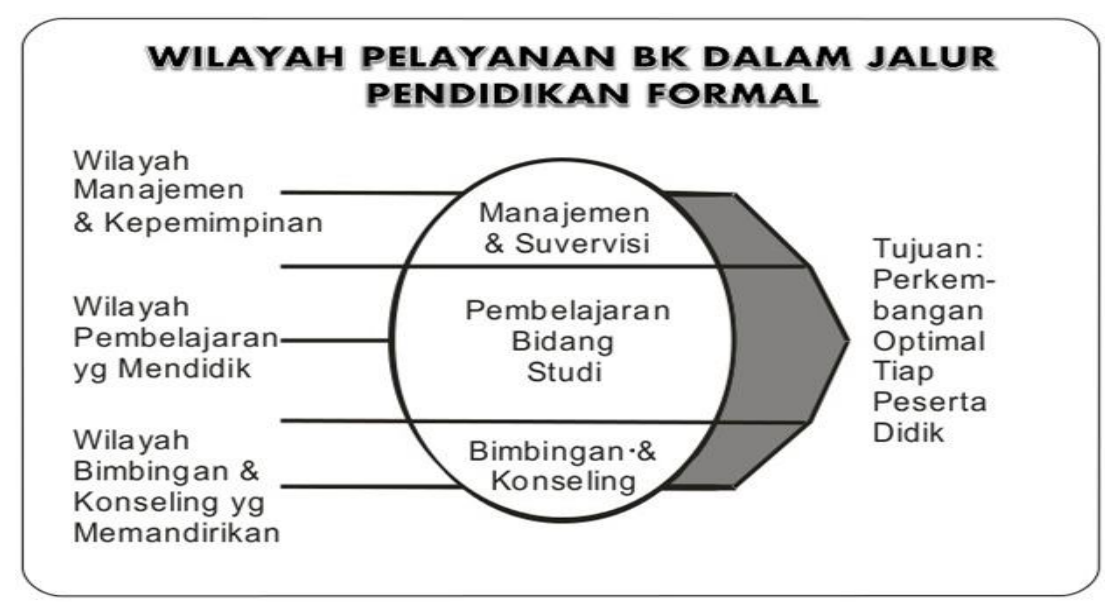

\section{Gambar 3. Porsi Bimbingan Dan Konseling Dalam Jalur Pendidikan}

Berdasarkan gambar di atas menunjukkan bahwa semua komponen mempunyai tujuan yang sama, yaitu perkembangan optimal tiap peserta didik. Bedanya, guru mata pelajaran menggarap wilayah pembelajaran yang mendidik, kita menggarap kemandirian siswa.

Dalam Panduan Oprasional Pelaksanaan Bimbingan Konseling juga dijelaskan perbedaan dan keterkaitan tugas Bimbingan dan Konseling dengan guru mata pelajaran, dapat dilihat pada table berikut

\begin{tabular}{|c|c|c|c|}
\hline \multicolumn{4}{|c|}{ Guru Mata Pelaiaran } \\
\hline 100 & Diments & Guru nata relajaran & $\begin{array}{l}\text { Konselor } \\
\text { Katu }\end{array}$ \\
\hline 1 & Wilayah garapan & $\begin{array}{l}\text { Jenjang pendidikan dasar } \\
\text { danpendidikan menengah }\end{array}$ & $\begin{array}{l}\text { Jenjang pendidikan dasar dan pendidikan } \\
\text { menengah }\end{array}$ \\
\hline 2 & Tujuan Umum & $\begin{array}{l}\text { Pencapaian tujuan pendidikan } \\
\text { Nasional }\end{array}$ & Pencapaian tujuan pendidikan Nasional \\
\hline 3 & Konteks Tugas : & $\begin{array}{l}\text { Pembelajaran yang mendidik } \\
\text { melalui mata pelajaran dengan } \\
\text { scenario guru }\end{array}$ & $\begin{array}{l}\text { Pelayanan yang mengarahkan } \\
\text { kemandirian dengan scenario konseli dan } \\
\text { konselor }\end{array}$ \\
\hline NO & Dimensi & Guru Mata Pelajaran & $\begin{array}{c}\begin{array}{c}\text { Guru Bimbingan Konseling atau } \\
\text { Konselor }\end{array} \\
\end{array}$ \\
\hline 4 & a. Fokus Kegiatan & $\begin{array}{l}\text { Pengembangan penguasaan } \\
\text { bidang studi } \\
\text { dan masalh-masalahnya }\end{array}$ & $\begin{array}{l}\text { Pengembangan potensi diri bidang pribadi, } \\
\text { sosial, belajar } \\
\text { karir, dan masalah-masalahnya. }\end{array}$ \\
\hline & b. Hubungan kerja & Alih tangan (referral) & Alih tangan (referral) \\
\hline 5 & Target Intervensi : & & \\
\hline & a. Individual & Minim & Utama \\
\hline & b. Kelompok & Pilihan Strategis & Pilihan Strategis \\
\hline & c. Klasikal & Utama & Minimal \\
\hline
\end{tabular}

Berdasarkan tabel di atas jelas terlihat perbedaannya, termasuk saat Bimbingan dan Konseling punya jam masuk kelas dan apa yang akan kita lakukan, serta materi apa dan tujuan masuk kelasnya. Yang paling berbeda adalah target intervensinya, dimana Bimbingan dan Konseling target intervensinya adalah individual. Jadi meskipun layanan dasar (klasikal kelompok) dilakukan, tetep mesti ditindaklanjuti dengan layanan individual. Dalam Buku Panduan Bimbingan dan Konseling di Sekolah terbitan P4TK tahun 2014, disebutkan bahwa Bimbingan Klasikal tidak hanya terbatas pada penyampaian satu atau dua permasalahan, akan tetapi mencakup berbagai permasalahan yang ada atau muncul di sekolah. Oleh karena itu, seorang guru Bimbingan dan Konseling dalam melaksanakan kegiatan layanan bimbingan klasikal ini hendaknya membangun interaksi psikopedagogik agar terjalin komunikasi yang 
harmonis dan mempunyai arti penting bagi tercapainya perkembangan peserta didik yang optimal.

Darimana materi kita peroleh? Guru mata pelajaran sudah jelas, bahwa perolehan materi diatur oleh permen mulai dari KI/KD nya. Guru Bimbingan dan Konseling dapat memulainya dari asesmen. Bimbingan dan Konseling sesuai dengan tugas perkembangan siswa asuh kita. Sampai saat ini masih berdasarkan kepada standar kompetensi kemandirian peserta didik (SKKPD) yang diterbitkan ABKIN tahun (2008). Untuk jenjang SMP ada 10 tugas perkembangan yang harus dicapai, untuk SMA ada 11 tugas perkembangan.

Peran guru Bimbingan dan Konseling di era pandemi COVID-19 dijelaskan, yaitu : pertama, guru Bimbingan dan Konseling melakukan pendampingan bagi peserta didik dalam upaya tercapainya perkembangan optimal dan utuh serta kemandirian dalam kehidupannya. Kedua, kegiatan pendampingan secara professional dilaksanakan oleh Guru Bimbingan dan Konseling berdasar ilmu Bimbingan dan Konseling disesuaikan dengan kondisi peserta didik serta yang terpenting adalah di era pandemi COVID-19 Guru Bimbingan dan Konseling tentunya lebih banyak menerapkan layanan berbasis teknologi informasi/online/daring. (Moh. Fahrozin, 2020).

Arah kerja Bimbingan dan Konseling di tengah pandemi maupun era new normal terdapat dua poin utama yakni, memandirikan pemecahan masalah siswa dan memperkuat kesehatan mental siswa. Ketika pertemuan tatap muka belum memungkinkan, guru Bimbingan dan Konseling dapat mulai membantu siswa untuk mandiri dalam memecahkan masalahnya. Guru Bimbingan dan Konseling dalam memberikan layanan penyelesaian masalah melalui komunikasi intensif dengan siswa secara daring. Dari langkah tersebut, guru Bimbingan dan Konseling dapat melanjutkan dengan memberi beberapa alternatif pemecahan masalah. (Asrofi, 2020)

Hasil Analisa asesmen bisa diketahui melalui kebutuhan siswa akan materi yang dibutuhkan. Misalnya, hasil asesmen menunjukan bahwa 75\% siswa kelas X belum percaya diri. Tidak memungkinkan jika dilakukan pemanggilan satu-satu siswa ke ruang Bimbingan dan Konseling untuk dikonseling dan dibangkitkan rasa percaya dirinya. Inilah alasan perlunya kita melakukan layanan bimbingan klasikal. Muncul pertanyaan, kapan kita melakukan layanan ini? Kan gak punya jam tatap muka? Pulang sekolah? Hanya orang-orang hebat yang bisa melakukan ini. Jika sudah waktunya pulang biasanya sih baik siswa maupun guru sudah mikir pulang juga. Nah, disinilah guru Bimbingan dan Konseling dituntut untuk berstrategi dan berinovasi. Gak bisa ketemu di kelas secara langsung, kita alihkan layanannya dengan menggunakan media seperti kulwap ini . Guru Bimbingan dan Konseling bisa membersamai siswa melalui group/luwes/fleksibel sesuai kebutuhan siswa di group, sehingga siswa merasakan kehadiran guru Bimbingan dan Konseling, sekaligus bisa mengetahui peta masalah yang terjadi. Hal tersebut bisa dijadikan sebagai pendukung dalam rangka pengumpulan data keaktifan belajar siswa, sekaligus menjadi catatan kehadiran siswa. Di sinilah kegiatan layanan Bimbingan dan Konseling sangat mungkin untuk dilaksanakan.

\section{KESIMPULAN}

Pelayanan Bimbingan Konseling bersifat For All, untuk semua siswa, sehingga tidak hanya terpusat pada siswa yang bermasalah. Agar tetap bisa memberikan layanan dalam situasi yang tidak memungkinkan bisa bertemu secara langsung/tatap muka, maka kegiatan layanan harus inovatif dan kreatif.

Arah kerja Bimbingan dan Konseling di tengah pandemi maupun era new normal terdapat dua poin utama yakni, memandirikan pemecahan masalah siswa dan memperkuat kesehatan mental siswa. Pada saat pertemuan tatap muka belum memungkinkan, maka guru Bimbingan dan Konseling dalam membeikan layanan penyelesaian masalah siswa melalui komunikasi intensif secara daring.

Kegiatan Bimbingan dan Konseling selama school from home bisa dilakukan melalui WatshApp sebagai media interaktif dalam pelayanannya, yang mampu menyumbang 
ketercapaian lebih efektif $80 \%$ dibandingkan dengan hanya ngobrol biasa dengan siswa pada group WhatsApp. Untuk ketercapaian dari target yang diprogramkan tentu saja tidak akan tercapai $100 \%$, akan tetapi dalam situasi yang tidak memungkinkan guru Bimbingan dan Konseling mengadakan pertemuan secara tatap muka, siswa sudah merasa adanya kehadiran guru Bimbingan dan Konseling dalam menemani, mendampingi mereka saat siswa menemui permasalahan ataupun kendala lain yang membutuhkan pemberian solusi.

\section{DAFTAR PUSTAKA}

Asrofi. (2020). Arah Kerja Konseling Siswa di Era New Normal. Universitas Sebelas Maret (UNS) Surakarta, https://uns.ac.id/id/uns-update/guru-besar-bk-uns-paparkan-arahkerja-konseling-

Departemen Pendidikan Nasional. (2007). Penataan Pendidikan Profesional Konselor dan Layanan Bimbingan Konseling Dalam Jalur Pendidikan Formal. Bandung : UPI

Fahrozin. M. (2020). Peran Guru BK di Era Pandemi COVID-19. Webinar. UNY

http://fip.uny.ac.id/berita/webinar-peran-guru-bk-di-era-pandemi-covid-19

Jallaludin. R (2007). Psikologi Komunikasi. Bandung : PT. Remaja Rosdakarya

Kementrian Pendidikan dan Kebudayaan Direktorat Jendral Guru dan Tenaga Kependidikan, (2014). Buku Panduan Bimbingan dan Konseling di Sekolah. Pusat Pengembangan dan Pemberdayaan Pendidik dan Tenaga Kependidikan (PPPPTK).

(2016). Panduan Oprasional Penyelenggaraan Bimbingan dan Konseling Sekolah Menengah Atas (SMA): Jakarta

Marjohan. (2013). Kepatuhan Siswa terhadap Disiplin dan Upaya Guru BK dalam Meningkatkanya melalui Layanan Informasi. Jurnal Ilmiah Konseling, Volume 2, No 1, Januari 2013 (220-224).

Nurhayati. (2020). Metode Pembelajaran Daring/ E-Learning Yang Efektif. Artikel. Jurusan Ilmu Pendidikan Psikologi dan Bimbingan Konseling.Universitas Pendidikan Ganesha Singaraja Indonesia.

Peraturan Menteri Pendidikan dan Kebudayaan Republik Indonesia Nomor 111. (2014). Pedoman Bimbingan dan Konseling pada Pendidikan Dasar dan Menengah.

Roestiyah. (2001). Strategi Belajar Mengajar. Jakarta: Rineka Cipta

Sadikin. A .Dkk. (2020).Pembelajaran Daring di Tengah Wabah Covid-19. BIODIK: Jurnal Ilmiah Pendidikan Biologi , 06 ( 02), 214 - 224.

Setiyanie. A. (2020). Cyber Counceling Bagi Gen Z Pada Masa New Normal. Webinar. Universitas Harapan Bangsa (UHB) Purwokerto, Banyumas, Jawa Tengah. https://republika.co.id/berita/qd7na5428/normal-baru-guru-bk-bisa-terapkankonseling-siber

Setyosari, P. (2007). Pembelajaran Sistem Online: Tantangan dan Rangsangan. Majalah Ilmiah Pembelajaran 2, 1-10. https://journal.uny.ac.id/index.php/mip/art icle/view/5992

Sofyana .L \& Rozaq.A . (2019). Pembelajaran Daring Kombinasi Berbasis WhatsApp pada Kelas Karyawan Prodi Teknik Informatika Universitas PGRI Madiun.. Jurnal Nasional Pendidikan Teknik Informatika. 8 (1),81-86.

Zhang, D., Zhao, J. L., Zhou, L., \& Nunamaker, J. F. (2004). Can e-learning replace classroom learning? Communications of ACM. https://doi.org/10.1145/986213.986216 